\title{
STUDI KOMPARATIF REAKSI PASAR SEBELUM DAN SESUDAH KENAIKAN HARGA BBM ATAS SAHAM LQ-45 DI BEI (EVEN STUDY PADA PERISTIWA KENAIKAN BBM TANGGAL 5 JANUARI 2017)
}

\author{
Ni Made Ardani \\ Jurusan Pendidikan Ekonomi, Fakultas Ekonomi \\ Universitas Pendidikan Ganesha \\ Singaraja, Indonesia \\ e-mail: madeardani25@yahoo.co.id
}

\begin{abstract}
Abstrak
Penelitian ini bertujuan untuk mengetahui perbedaan abnormal return sebelum dan sesudah kenaikan harga Bahan Bakar Minyak (BBM) tanggal 5 Januari 2017, dan perbedaan volume perdagangan saham sebelum dan sesudah kenaikan harga BBM tanggal 5 Januari 2017. Penelitian ini merupakan penelitian even study dengan menggunakan 45 perusahaan yang termasuk dalam kategori LQ45 periode Agustus 2016 - Januari 2017 sebagai subjek penelitian. Data dikumpulkan menggunakan metode dokumentasi. Data dianalisis dengan uji beda t-test (paried samples test) untuk hipotesis pertama dan Wilcoxon Signed Rank untuk hipotesis kedua. Hasil penelitian menunjukan bahwa, tidak terdapat perbedaan abnormal return sebelum dan sesudah kenaikan harga BBM dengan hasil nilai Sig. (2-tailed) sebesar 0,582 > a 0,05, demikian pula tidak terdapat perbedaan volume perdagangan saham sebelum dan sesudah kenaikan harga BBM dengan hasil nilai Asymp. Sig. (2 - tailed) sebesar 0,099 > a 0,05.
\end{abstract}

Kata kunci : abnormal return, reaksi pasar, volume perdagangan saham

\begin{abstract}
The study aims to determine the difference of abnormal return before and after the increase of the fuel price on January 5, 2017, and difference of stock trading volume before and after the increase of the fuel price on January 5, 2017. This research is an even study which is using 45 companies listed in the LQ45 Agust 2016 - January 2017 period as subject. The data were collected using documentation method. Data were analyzed by using t-test (paried samples test) for the first hypothesis and wilcoxon signed rank for the second hypothesis. The result of research shows that, there is no difference of abnormal return before and after the increase of the fuel with result of sig value, the value of (2-Tailed) of $0,582>\alpha 0,05$, similarly there is no difference in the volume of stock trading before and after the increase of the fuel with Asym value.Sig (2-Tailed) of 0,099 > 0,05.
\end{abstract}

Keywords : abnormal return, market reaction, stock trading volume

\section{PENDAHULUAN}

Pasar modal di Indonesia dalam perkembangannya telah menunjukan sebagai bagian dari instrumen perekonomian yang mempertemukan modal dari pihak yang memiliki dana dengan pihak yang membutuhkan dana. Pasar modal merupakan sarana atau wadah untuk mempertemukan antara penjual dan pembeli instrumen keuangan dalam rangka investasi (Hadi, 2013). Berdasarkan Undang-Undang pasar modal, pasar modal memiliki peran strategis dalam pembangunan nasional dan sebagai salah satu sumber pembiayaan bagi dunia usaha dan wahana investasi bagi masyarakat. 
Pasar modal juga memiliki peran sebagai alat untuk mengalokasikan sumber daya ekonomi secara optimal. Selain itu, Menurut Untung (2011), pasar modal memiliki beberapa peran strategis bagi pihak yang memerlukan dana maupun bagi pemerintah yaitu sebagi sumber alternatif penghimpun dana, selain sistem perbankan yang selama ini dikenal sebagai sumber penghimpun dana secara konvensiaonal, sebagai alternatif investasi para pemodal/investor, yaitu memberikan kesempatan kepada para pemodal untuk membentuk portopolio investasi dan pasar modal akan mendorong perkembangan investasi. Menurut Sadono (2012: 121), investasi dapat diartikan sebagai pengeluaran atau penanaman modal perusahaan untuk membeli barang barang modal dan perlengkapan-perlengkapan produksi untuk menambah kemampuan memproduksi barang dan jasa yang tersedia dalam perekonomian. Investasi merupakan komitmen atas sejumlah dana atau sumber daya lainnya yang dilakukan saat ini, dengan tujuan memperoleh sejumlah keuntungan di masa akan datang (Tadelilin, 2010).

Pasar modal tidak terlepas dari peran investor sebagai pemodal yang memberi dan menyalurkan dananya dalam suatu perusahaan. Investor merupakan pemodal yang akan membeli atau menanamkan modalnya pada suatu perusahaan, sehingga perusahaan akan lebih mudah untuk memperoleh dana modal dalam menjalankan perusahaannya. Namun keputusan investor untuk menanamkan modalnya sangat dipengaruhi oleh laba atau keuntungan yang yang di dapat dari saham yang diinvestasikan pada suatu perusahaan. Selain itu, keputusan investor dalam menanamkan modalnya di pasar modal, juga membutuhkan adanya keterbukaan informasi sebagai bahan pertimbangan dalam pengambilan keputusan investasi. Informasi merupakan hal penting bagi pelaku bisnis karena informasi pada dasarnya menyediakan catatan atau gambaran keadaan perusahaan baik untuk keadaan masa lalu, saat ini, maupun keadaan masa yang akan datang.

Informasi yang dibutuhkan investor dalam pengambilan keputusan investasi adalah informasi yang lengkap, relevan akurat dan tepat waktu. Dengan kata lain, keputusan yang dilakukan oleh investor dalam berinvestasi merupakan reaksi atas informasi dari suatu peristiwa yang terjadi atau peristiwa yang di terima oleh pasar.

Informasi dari peristiwa yang dipublikasikan sebagai suatu pengumuman akan memberikan sinyal dalam pengambilan keputusan investasi investor (Hartono, 2013). Sinyal merupakan tindakan yang di ambil manajemen perusahaan yang memberi petunjuk bagi investor tentang bagaimana manajemen memandang prospek perusahaan (Brigham, 2001). Tandakantindakan perubahan respon pasar dapat dilihat dari reaksi harga saham, dari reaksi harga saham tersebut dapat memicu terjadinya reaksi pasar. Untuk mengukur reaksi pasar terhadap suatu peristiwa atau informasi yang ditunjukkan dengan menggunakan return sebagai nilai perubahan harga atau dengan menggunakan return tak normal (abnormal return). Abnormal return adalah selisih return sesungguhnya dan return yang diharapkan (Hartono, 2016). Menurut Samsul (2006), abnormal return adalah selisih antara return yang diharapkan dan return yang diharapkan (expected return) yang dapat terjadi sebelum informasi resmi diterbitkan atau telah terjadi kebocoran informasi (leakage of information) sesudah informasi resmi diterbitkan. Abnormal return terjadi dikarenakan adanya informasi yang tidak terduga dan terdapat kebocoran informasi, sehingga menghasilkan adanya return yang tidak normal. Jika digunakan abnormal return maka dapat dikatakan bahwa suatu pengumuman yang mempunyai kandungan informasi akan memberikan abnormal return kepada pasar. Sebaliknya yang tidak mengandung informasi tidak memberikan abnormal 
return kepada pasar. Abnormal return dapat digunakan sebagai alat ukur dalam menilai reaksi pasar terhadap informasi yang dikeluarkan atau dipublikasikan dari suatu pengumuman (Hartono, 2016). Selain menggunakan abnormal return, untuk melihat reaksi pasar terhadap suatu peristiwa yang informasinya dipublikasikan sebagai suatu pengumuman yang berkaitan dengan suatu saham juga dapat ditunjukkan dari perubahan volume perdagangan saham. Volume perdagangan saham merupakan suatu instrumen yang dapat digunakan untuk melihat reaksi pasar modal terhadap informasi melalui parameter pergerakan volume saham yang diperdagangkan di pasar (Sutrisno 2000). Volume perdagangan saham adalah banyaknya jumlah lembar saham yang diperdagangkan di bursa pada suatu waktu tertentu (Yantini \& Rochadian 2013). Trading volume activity (TVA) merupakan instrumen yang dapat digunakan untuk melihat reaksi pasar modal terhadap infomasi atau peristiwa melalui parameter pergerakan aktivitas volume perdagangan di pasar. Aktivitas volume perdagangan saham digunakan untuk melihat apakah investor individual menilai informasi yang ada, dalam arti apakah informasi tersebut membuat keputusan investor pada kondisi normal. Aktivitas volume perdagangan saham adalah perbandingan antara saham yang diperdagangkan pada waktu tertentu dengan jumlah saham yang beredar di pasar.

Reaksi pasar dalam pasar modal yang terjadi akibat adanya informasi tidak terlepas dari pengaruh yang berkembang di lingkungannya, baik yang terjadi di lingkungan ekonomi mikro maupun lingkungan ekonomi makro yang dapat mempengaruhi gejolak di pasar modal. Lingkungan ekonomi mikro yaitu peristiwa atau keadaan para emiten, seperti pembagian deviden dan pengembangan produk baru sedangkan lingkungan ekonomi makro yaitu seperti kebijakan moneter, dan kebijakan fiskal serta regulasi pemerintah.

Regulasi pemerintah merupakan hal penting yang menjadi pertimbangan investor dalam melalukan investasi di pasar modal. Seperti salah satu regulasi pemerintah tentang Bahan Bakar Minyak (BBM). BBM merupakan komoditas yang memegang peranan penting dalam kegiatan ekonomi suatu negara. BBM memiliki peranan sebagai bahan pendukung proses produksi bagi industri. Kenaikan harga BBM menyebabkan biaya produksi semakin meningkat, sehingga keuntungan atau laba perusahaan akan mengalami penurunan. Oleh karena itu, kenaikan harga BBM tidak hanya bedampak pada perusahaan pada khususnya, tetapi juga pada masyarakat kecil pada umumnya.

Dalam hal ini, pemerintah kembali menaikkan harga bahan bakar minyak yaitu sebesar Rp 300 per liter pada tanggal 5 Januari 2017. Dimana harga solar semula Rp 5.150 menjadi Rp 5.450, pertamina dex semula Rp 8.200 menjadi Rp 8.500, pertalite semula $R p 7.050$ menjadi Rp 7.350, pertamax semula $R p$ 7.750 menjadi $\mathrm{Rp}$ 8.050, dan pertamx turbo Rp 9.100 dari 8.800 sedangkan harga premium tetap $\mathrm{Rp} 6.650$.

Regulasi pemerintah dalam menaikkan harga BBM pada tanggal 5 Januari 2017 merupakan peristiwa yang informatif. Regulasi pemerintah dalam menaikkan harga BBM ikut berpengaruh terhadap harga saham dan volume perdagangan saham di pasar saham, seperti terjadinya fluktuasi harga saham pada periode sebelum diterimanya informasi dengan sesudah diterimanya informasi oleh pelaku pasar. Harga saham yang berfluktuasi dapat mempengaruhi perilaku investor dalam melakukan jual beli saham di pasar modal, sehingga memicu terjadinya reaksi pasar.

Berdasarkan latar belakang masalah di atas tujuan penelitian ini adalah untuk mengetahui ada tidaknya perbedaan abnormal return sebelum dan sesudah peristiwa kenaikan harga bahan 
bakar minyak tanggal 5 Januari 2017, dan ada tidaknya perbedaan volume perdagangan saham sebelum dan sesudah peristiwa kenaikan harga bahan bakar minyak tanggal 5 Januari 2017.

\section{METODE}

Penelitian ini merupakan penelitian studi peristiwa (even study) yaitu studi yang mempelajari reaksi pasar terhadap suatu peristiwa (event) yang informasinya dipublikasikan sebagai suatu pengumuman. Even study dapat digunakan untuk menguji kandungan informasi (Informasi contens) dari suatu pengumuman dan dapat dan juga dapat digunakan untuk menguji efesiensi pasar bentuk setengah kuat (Hartono, 2016: 623).

Peristiwa yang di uji dalam penelitian ini adalah peristiwa kenaikan harga BBM pada tanggal 5 Januari 2017.

Periode pengamatan dalam penelitian ini adalah 5 hari sebelum pengumuman kenaikan harga BBM $(\mathrm{H}-5)$ dan 5 hari setelah kenaikan harga BBM $(\mathrm{H}+5)$ tanggal 5 Januari 2017. Penentuan periode peristiwa ini diharapkan pasar sudah bereaksi terhadap pengumuman peristiwa kenaikan harga BBM, selain itu menghindari pengaruh dari faktor-faktor lain yang dapat mempengaruhi harga saham dan volume perdagangan saham, seperti adanya pengumuman deviden, rumor dan sentimen pasar, stock split, dan lain-lain yang dapat menyebabkan harga saham dan volume perdagangan saham suatu perusahaan mengalami perubahan. Periode pengamatan penelitian ini dapat dilihat pada gambar 1.

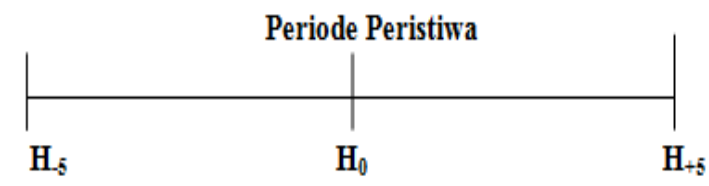

Gambar 1. Periode Pengamatan

Keterangan:

H-5 : Hari bursa ke-5 sebelum kenaikan harga BBM

HO : Hari kenaikan harga BBM
$\mathrm{H}+5$ : Hari bursa ke-5 sesudah kenaikan harga BBM

Variabel penelitian adalah objek penelitian, atau apa yang menjadi titik perhatian suatu penelitian (Arikunto, 2006) sedangkan Sugiyono (2007), mendefinisikan variabel sebagai segala sesuatu yang berbentuk apa saja yang ditetapkan oleh peneliti untuk dipelajari sehingga diperoleh informasi tentang halhal tersebut, kemudian ditarik kesimpulannya. Terdapat dua variabel yang diukur dalam penelitian ini yaitu abnormal return dan volume perdagangan saham. Abnormal return adalah selisih return sesungguhnya dan return yang diharapkan (Hartono 2016). Abnormal return terjadi dikarenakan adanya informasi yang tidak terduga atau terdapat kebocoran informasi, sehingga menghasilkan adanya return yang tidak normal. Sedangkan volume perdagangan saham merupakan suatu instrumen yang dapat digunakan untuk melihat reaksi pasar modal terhadap informasi melalui parameter pergerakan volume saham yang diperdagangkan di pasar (Sutrisno 2000). Aktivitas volume perdagangan saham adalah perbandingan saham yang diperdagangkan dengan jumlah saham yang beredar di pasar.

Populasi adalah keseluruhan jumlah yang terdiri atas objek atau subjek yang mempunyai karakteristik dan kualitas tertentu yang ditetapkan oleh peneliti untuk diteliti dan kemudian ditarik kesimpulannya (Sujarweni, 2014). Populasi dalam penelitian ini adalah keseluruhan saham yang tercatat dalam saham LQ-45 periode Agustus 2016 Januari 2017.

Sampel adalah bagian dari sejumlah karakteristik yang dimiliki oleh populasi yang digunakan untuk penelitian (Sujarweni, 2014). Karena jumlah populasi 45 perusahaan, maka sampel yang digunakan adalah keseluruhan dari populasi yang ada yaitu 45 perusahaan yang termasuk dalam kategori saham LQ45 periode Agustus 2016 - Januari 2017. 
Jenis data yang digunakan dalam penelitian ini adalah data kuantitatif, yang berupa data harga saham harian dan jumlah volume perdagagangan saham pada perusahaan yang termasuk dalam kategori saham LQ-45 periode Agustus 2016 - Januari 2017.

Data menurut sumbernya terdiri dari data primer dan data skunder. Data primer yaitu data asli yang dikumpulkan oleh peneliti untuk menjawab masalah penelitian, sedangkan data skunder adalah data yang bersuber dari catatan dari perusahaan dan sumber lainnya ( Sunyoto, 2013). Data yang digunakan adalah data skunder yang berupa dokumen dalam bentuk data transaksi harian di bursa efek indonesia.

Metode pengumpulan data merupakan teknik atau cara yang dilakukan oleh peneliti untuk mengumpulkan data. Metode pengumpulan data dalam penelitian ini adalah dokumentasi yang berhubungan dengan data laporan perdagangan saham harian perusahaan yang terdaftar dalam kategori saham LQ-45 periode Agustus 2016 - Januari 2017.

Teknik analisa data yang digunakan dalam penelitian ini adalah menggunakan uji Paried Samples t-test apabila data terdistribusi normal dan uji Wilcoxon Signed Rank apabila data tidak terdistribusi normal. Uji Paried samples $t$ tes adalah uji beda sampel berpasangan yaitu memiliki subjek yang sama, namun memiliki perlakuan berbeda. Wilcoxon Signed Rank Test adalah pengujian hipotesis statistik non-parametrik digunakan ketika membandingkan dua sampel berhubungan, sampel yang sama untuk menilai apakah ada perbedaan dua pengukuran pada sampel yang sama (Suryani \& Hendryadi, 2015). Ciri-ciri yang ditemui pada kasus yang berpasangan yaitu satu individu (objek penelitian) dikenai dua perlakuan yang berbeda. Walaupun menggunakan individu yang sama, peneliti tetap memperoleh dua macam data sampel, yaitu data dari perlakuan pertama dan data dari perlakuan kedua. Dengan demikian suatu pengaruh dapat diketahui dengan cara membandingkan kondisi objek penelitian sebelum dan sesudah perlakuan (Ghozali, 2009).

Analisis data dalam penelitian ini dilakukan melaluli tahapan-tahapan berikut.

Tahap pertama menghitung actual return secara sistematis yang dihitung dengan rumus:

$$
\mathrm{Ri}, \mathrm{t}=\frac{(\mathrm{Pit}-\mathrm{Pi}, \mathrm{t}-1)}{\mathrm{Pi}, \mathrm{t}-1}
$$

(Hartono, 2016)

Keterangan:

$\mathrm{Ri}, \mathrm{t} \quad$ : return saham harian sekuritas $\mathrm{i}$ pada periode $t$

$\mathrm{Pi}, \mathrm{t} \quad$ : harga saham i pada periode $\mathrm{t}$

$\mathrm{Pi}, \mathrm{t}-1$ : harga saham i pada periode $\mathrm{t}-1$

Tahap kedua menghitung return pasar harian. Market return adalah tingkat keuntungan seluruh saham yang terdaftar di pasar modal. Market return diwakili oleh Indeks Harga Saham Gabungan (IHSG). IHSG menunjukkan indeks harga saham yang terdaftar di pasar modal yang dapat diformulasikan dengan rumus:

$$
\mathrm{Rmt}=\frac{\text { IHSGt }-\mathrm{IHSGt}-1}{\mathrm{IHSGt}-1}
$$

(Hartono, 2016)

Keterangan:

Rmt : return pasar pada hari t

IHSGt : Indeks Harga Saham Gabungan pada periode $\mathrm{t}$

HSGt-1: Indeks Harga Saham Gabungan pada perode t-1

Tahap ketiga menghitung ecpected return. Dalam penelitian ini menggunakan model disesuaikan pasar (market-ajusted model). Market-Ajusted Model menganggap bahwa penduga yang terbaik untuk mengestimasi return suatu sekuritas adalah return indeks pasar pada saat tersebut (Hartono, 2016:659). Return pasar yang digunakan dalam penelitian ini adalah Indeks Harga Saham Gabungan (IHSG) harian, yaitu dengan rumus:

$$
\mathrm{E}[\mathrm{Ri}, \mathrm{t}]=\mathrm{RM}, \mathrm{i}, \mathrm{t}
$$


Keterangan:

$E[R i, t] \quad$ : return ekspetasi sekuritas i pada periode $\mathrm{t}$

RM,i,t : return pasar sekuritas ke-i pada perode estimasi ke-t

Tahap keempat menghitung abnormal return, yaitu dihitung dengan rumus:

$$
A R i, t=R i, t-E[R i, t]
$$

(Hartono, 2016)

Keterangan:

ARi,t : abnormal return sekuritas ke-i periode peristiwa ke-t

$\mathrm{Ri}, \mathrm{t}$ : return realisasi yang terjadi untuk sekuritas ke-i pada periode peristiwa ke-t

$\mathrm{E}[\mathrm{ri}, \mathrm{t}] \quad$ : return ekspetasi sekuritas ke-i untuk periode peristiwa ke-t.

Tahap kelima menghitung volume perdagangan saham, dengan menggunakan instrumen aktivitas volume perdagangan, dapat dihitung dengan rumus:

$T V A=\frac{\text { jumlah saham yang diperdagangan saat } \mathrm{t}}{\text { jumlah saham yang beredar }}$

(Yantini \& Rochadian, 2013)

Tahap keenam melakukan uji normalitas data, uji normalitas adalah uji yang dilakukan dengan tujuan untuk menilai sebaran data pada kelompok data atau variabel, apakah data tersebut berdistribusi normal atau tidak berdistribusi normal. Untuk menguji normalitas suatu data dilakukan dengan menggunakan statistik nonparametrik dengan metode satu sampel one-sample Kolmogorof-smirnov (Suyana, 2016). Uji ini digunakan untuk menguji apakah data yang digunakan terdistribusi secara normal atau tidak dan menentukan uji selanjutnya yang harus digunakan terhadap data yang terdistribusi normal dan data yang tidak terdistribusi normal.

Tahap ketujuh melakukan uji statistik, uji statistik yang digunakan untuk mengetahui apakah terdapat perbedaan abnormal return sebelum dan sesudah kenaikan harga bahan bakar minyak tanggal 5 Januari 2017 adalah uji paried sample T-Test dengan menggunakan program SPSS 16.0 for windows, apabila data yang digunakan terdistribusi normal dan apabila data yang digunakan tidak terdistribusi normal maka uji yang digunakan adalah Wilcoxon Signed Rank untuk sampel berpasangan. Tingkat signifikan atau nilai alfa ( $\alpha$ ) yang digunakan adalah 0,05 dan df $=n-1$, dengan kriteria pengujian sebagai berikut. Jika probabilitas lebih kecil dari a 0,05 mka $\mathrm{H}_{1}$ di terima, dan jika probabilitas lebih besar dari a 0,05 maka $\mathrm{H}_{2}$ di tolak

Uji statistik yang digunakan untuk mengetahui apakah terdapat perbedaan volume perdagangan saham sebelum dan sesudah peristiwa kenaikan harga bahan bakar minyak tanggal 5 Januari 2017, adalah uji paried sample T-Test menggunakan program SPSS 16.0 for windows, apabila data yang digunakan terdistribusi normal dan apabila data yang digunakan tidak terdistribusi normal, maka uji yang digunakan adalah uji Wilcoxon Signed Rank untuk sampel berpasangan. Untuk tingkat signifikan atau nilai alfa (a) yang digunakan adalah 0,05 dan $\mathrm{df}=\mathrm{n}-1$ dengan kriteria pengujian sebagai berikut. Jika probabilitas lebih kecil dari a 0,05 maka $\mathrm{H}_{2}$ di terima dan jika probabilitas lebih besar dari a 0,05 maka $\mathrm{H}_{2}$ di tolak.

\section{HASIL DAN PEMBAHASAN Hasil}

Berdasarkan uji normalitas data abnormal return sebelum dan abnormal return sesudah kenaikan harga bahan bakar minyak tanggal 5 Januari 2017 dengan menggunakan metode OneSample Kolmogorov-Smirnov Test menggunakan program SPPS 16.0 for window, diperoleh hasil uji normalitas yaitu nilai dari asimp.sig (2-tailed) masingmasing sebelum dan sesudah kenaikan harga BBM tanggal 5 Januari 2017 sebesar 0,987 dan 0,806. Hal ini menunjukkan nilai dari asymp.sig (2-tailed) nilainya lebih besar dari $\alpha=0,05 \quad(5 \%)$, sehingga data dapat dikatakan terdistribusi secara normal. Sehingga pengujian selanjutnya dapat dilakukan dengan menggunakan uji beda $t$-test (paried samples test). Secara rinci hasil uji 
normalitas menggunakan program dapat dilihat pada tabel 1.

Tabel 1. Hasil Uji Normalitas

One-Sample Kolmogorov-Smirnov Test

\begin{tabular}{|c|c|c|c|}
\hline & & AR.SEBELUM & AR.SESUDAH \\
\hline $\mathrm{N}$ & & 45 & 45 \\
\hline \multirow[t]{2}{*}{ Normal Parameters ${ }^{a}$} & Mean & .00007787 & .00017493 \\
\hline & Std. Deviation & .003406601 & .002308045 \\
\hline \multirow[t]{3}{*}{ Most Extreme Differences } & Absolute & .067 & .096 \\
\hline & Positive & .067 & .096 \\
\hline & Negative & -.064 & -.055 \\
\hline Kolmogorov-Smirnov Z & & .451 & .641 \\
\hline Asymp. Sig. (2-tailed) & & .987 & .806 \\
\hline
\end{tabular}

a. Test distribution is Normal

Hasil pengolahan data abnormal return sebelum dan sesudah kenaikan harga BBM tanggal 5 januari 2017 dengan menggunakan uji beda t-test (paried samples test), menunjukan bahwa nilai dari asymp.sig (2-tailed) sebesar 0,852 > 0,05 (95\%). Hal ini menunjukan bahwa $\mathrm{H}_{1}$ di tolak. Sehingga dapat diketahui bahwa tidak terdapat perbedaan abnormal return sebelum dan sesudah kenaikan BBM tanggal 5 Januari 2017. Secara rinci analisis yang dilakukan dengan program SPSS 16.0 for windows dapat dilihat pada tabel 2.

Tabel 2. Hasil uji beda t-test

Paired Samples Test

Paired Differences

\begin{tabular}{|c|c|c|c|c|c|c|c|}
\hline & \multirow[b]{2}{*}{ Mean } & \multirow[b]{2}{*}{$\begin{array}{c}\text { Std. } \\
\text { Deviation }\end{array}$} & \multirow[b]{2}{*}{$\begin{array}{l}\text { Std. Error } \\
\text { Mean }\end{array}$} & \multicolumn{2}{|c|}{$\begin{array}{c}95 \% \text { Confidence Interval } \\
\text { of the Difference }\end{array}$} & \multirow[b]{2}{*}{$\mathrm{T}$} & \multirow{2}{*}{$\begin{array}{l}\text { Sig. } \\
(2- \\
\text { tailed } \\
\text { df })\end{array}$} \\
\hline & & & & Lower & Upper & & \\
\hline $\begin{array}{ll}\text { Pair } & \text { AR.SE } \\
1 & \text { BELUM } \\
& - \\
& \text { AR.SE } \\
& \text { SUDAH }\end{array}$ & $-9.706222222 E-5$ & $\begin{array}{r}.00347720 \\
6\end{array}$ & $\begin{array}{r}.00051835 \\
1\end{array}$ & -.001141731 & $\begin{array}{r}.00094760 \\
6\end{array}$ & 187 & $44 \quad .852$ \\
\hline
\end{tabular}

Berdasarkan hasil uji normalitas data trading volume aktivity sebelum dan trading volume aktivity sesudah kenaikan harga BBM tanggal 5 Januari 2017 dengan metode One-Sample KolmogorovSmirnov Test dengan menggunakan program SPSS 16.0 for windows, diperoleh hasil nilai dari asymp.sig (2tailed) masing-masing sebelum dan sesudah kenaikan harga BBM sebesar
0,005 dan 0,003 . Hal ini menunjukan bahwa nilainya lebih kecil dari $\alpha=0,05$ (5\%) sehingga data dikatakan tidak terdistribusi secara normal. Jadi pengujian selanjutnya menggunakan uji Wilcoxon Signed Rank untuk sampel berpasangan. Secara rinci hasil uji normalitas trading volume aktivity dengan program SPSS 16.0 for windows dapat dilihat pada tabel 3. 


\begin{tabular}{|c|c|c|c|}
\hline & & TVA.SEBELUM & TVA.SESUDAH \\
\hline $\mathrm{N}$ & & 45 & 45 \\
\hline \multirow[t]{2}{*}{ Normal Parameters ${ }^{a}$} & Mean & .00194682 & .00184789 \\
\hline & Std. Deviation & .002686458 & .002848940 \\
\hline \multirow[t]{3}{*}{ Most Extreme Differences } & Absolute & .259 & .272 \\
\hline & Positive & .259 & .272 \\
\hline & Negative & -.248 & -.268 \\
\hline Kolmogorov-Smirnov Z & & 1.737 & 1.827 \\
\hline Asymp. Sig. (2-tailed) & & .005 & .003 \\
\hline
\end{tabular}

Hasil pengolahan data trading volume aktivity sebelum dan sesudah kenaikan harga BBM tanggal 5 Januari 2017 dengan menggunakan Wilcoxon Signed Rank menunjukan bahwa nilai dari asymp.sig (2-tailed) sebesar 0,009> dari $\alpha$ $=0,05(95 \%)$. Hal ini menunjukan bahwa
$\mathrm{H}_{2}$ ditolak. Sehingga dapat diketahui bahwa tidak terdapat perbedaan volume perdagangan saham sebelum dan sesudah kenaikan harga BBM tanggal 5 Januari 2017. Secara rinci hasil uji Wilcoxon Signed Rank dengan SPSS dapat dilihat pada tabel 4.

Tabel 4. Hasil Uji Wilcoxon Signed Rank

Test Statistics ${ }^{b}$

\begin{tabular}{l} 
Asymp. Sig. (2-tailed) \\
\hline a. Based on positive ranks. \\
b. Wilcoxon Signed Ranks Test
\end{tabular}

\section{Pembahasan}

Dari hasil penelitian diketahui bahwa tidak terdapat perbedaan reaksi pasar modal sebelum dan sesudah kenaikan harga bahan bakar minyak tanggal 5 Januari 2017 yang diukur dengan menggunakan abnormal return dan volume perdagangan saham.

Hasil penelitian ini tidak sesuai dengan penelitian yang dilakukan oleh Simanjuntak (2008), dimana hasil penelitiannya menunjukkan adanya perbedaan reaksi pasar sebelum dan sesudah melakukan Internet Financial Reporting, baik yang diukur dengan volume perdagangan saham, harga saham dan abnormal return saham.

Peristiwa kenaikan harga bahan bakar minyak tidak menjadi faktor utama yang menyebabkan perubahan harga saham di bursa. perubahan harga saham bisa disebabkan oleh faktor dari dalam yaitu seperti laba perusahaan, pertumbuhan aktiva, likuiditas, dan penjualan barang produksi, maupun faktor dari luar sekuritas yang bersangkutan seperti pergerakan suku bunga, fluktuasi nilai tukar uang, rumor dan sentimen pasar dan penggabungan usaha.

Secara umum pengumuman kenaikan harga bahan bakar minyak memang merupakan kabar buruk (bad news) bagi dunia usaha. Namun informasi kenaikan harga BBM bukan merupakan informasi yang dijadikan pedoman oleh investor untuk melakukan investasi di pasar modal. Selain itu, pengumuman kenaikan harga BBM tidak memiliki kandungan informasi yang dapat mempengaruhi keputusan investor dalam 
berinvestasi di pasar modal. Sehingga pasar tidak terlalu menganggap bahwa informasi dari peristiwa kenaikan harga BBM sebagai peristiwa yang dapat mempengaruhi harga saham dan volume perdagangan saham, sehingga investor tidak mau mengambil resiko dengan terlalu cepat mengambil keputusan dari suatu informasi eksternal dan internal yang di dapat. Kehati-hatian investor inilah yang menyebabkan pasar tidak bereaksi secara signifikan karena investor tidak ingin mendapat kerugian dari keputusan investasi yang mereka lakukan.

Penelitian ini tidak mendukung teorinya Hartono (2016), yaitu teori even study yang menyatakan bahwa even study merupakan studi yang mempelajari reaksi pasar terhadap suatu peristiwa (event) yang informasinya di publikasikan sebagai suatu pengumuman. even study dapat digunakan untuk menguji kandungan informasi (information content) dari suatu pengumuman.

Berdasarkan hal tersebut dapat dikatakan bawa pasar modal di Indonesia tidak bereaksi terhadap semua informasi dari peristiwa yang terjadi, namun pasar modal akan bereaksi terhadap peristiwa tertentu saja, sehingga even study dapat dilakunan untuk menguji peristiwa yang akan direspon oleh pasar modal di Indonesia.

\section{SIMPULAN DAN SARAN Simpulan}

Berdasarkan hasil penelitian dan pembahasan yang telah dilakukan, maka dapat ditarik kesimpulan bahwa tidak terdapat perbedaan abnormal return sebelum dan sesudah kenaikan harga bahan bakar minyak tanggal 5 Januari 2017 dengan hasil nilai sig (2-tailed) sebesar $0,582>\alpha 0,05$. tidak terdapat perbedaan volume perdagangan saham yang di ukur menggunakan instrumen aktivitas volume perdagangan saham (trading volume aktivity) sebelum dan sesudah kenaikan harga bahan bakar minyak tanggal 5 Januari 2017 dengan hasil nilai Asym.Sig. (2-tailed) sebesar $0,099>\alpha 0,05$. Tidak terdapat perbedaan reaksi pasar sebelum dan sesudah kenaikan bahan bakar minyak tanggal 5 Januari 2017 baik yang diukur menggunakan abnormal return maupun yang diukur dengan volume perdagangan saham.

\section{Saran}

Berdasarkan simpulan di atas maka saran yang dapat diberikan yaitu bagi investor, investor agar memperhatikan informasi-informasi yang ada, baik informasi ekonomi maupun non ekonomi sebagai acuan dalam keputusan investasi. Bagi peneliti selanjutnya yang ingin melakukan penelitian di Bursa Efek Indonesia, diharapkan agar memperluas sampel penelitian yang digunakan dan meneliti perusahaan yang memiliki karakteristik berbeda dengan perusahaan LQ-45.

\section{DAFTAR PUSTAKA}

Arikunto, S. 2006. Metodelogi Penelitian. Yogyakarta: Bina Aksara.

Brigham, Eugine F. 2001. Manajemen Keuangan. Jakarta: Erlangga

Ghozali, Imam. 2009. Aplikasi Analisis Multivariate dengan program SPSS. Edisi 4. Semarang: Badan Penerbit Universitas Diponegoro

Hartono, Jogiyanto. 2013. Teori Portofolio dan Analisis Investasi. (Edisi Kedelapan). Yogyakarta: BPFE Yogyakarta

------. 2016. Teori Portofolio dan Analisis Investasi. (Edisi Kesepuluh). Yogyakarta: BPFE Yogyakarta.

Hadi, Nor. 2013. Pasar Modal: Acuan Teoritis dan Praktis Investasi di Instrumen Keuangan Pasar Modal. Yogyakarta: Graha Ilmu.

Juliana, Zessy. 2008. Pengaruh Sebelum dan Sesudah Internet Financial Reporting Terhadap Volume Perdagangan Saham, Harga Saham, dan Abnormal Return 
Saham pada Perusahaan Manufaktur di BEl. Skripsi (Tidak diterbitkan). Departemen akuntansi, Fakultas Ekonomi dan Bisnis, Universitas Sumatra Utara.

Sadono, Sukirno. 2012. Makro Ekonomi Teori Pengantar. Edisi Ketiga. Jakarta: Erlangga.

Samsul, Mohamad. 2006. Pasar Modal dan Manajemen Portopolio. Jakarta: Erlangga.

Sugiyono. 2007. Statistika untuk Penelitian. Bandung: Alfabeta.

Sujarweni, Wiratna. 2014. Metodelpgi Penelitian. Yogyakarta: PT Pustaka Baru.

Sunyoto, Danang. 2013. Metode Penelitian Akuntansi. Bandung: PT Refika Aditama

Suryani \& Hendrayadi. 2015. Metode Riset Kuantitatif: Teori dan Aplikasi pada Penelitian Bidang Manajemen dan Ekonomi Islam. Jakarta: PRENADAMEDIA GRUP.

Sutrisno, Wang. 2000. Manajemen Keuangan: Teori, Konsep, dan Aplikasi. Yogyakarta: Ekonisia.

Tandelilin, Eduardus. 2010. Portofolio dan Investasi Teori dan Aplikasi, Edisi Pertama. Yogyakarta: Kanisius.

Utama, Made Suyana. 2016. Aplikasi analisis Kuantitatif: Untuk Ekonomi dan Bisnis. Denpasar: CV Sastra Utama.

Untung, Budi. 2011. Hukum Bisnis Pasar Modal. Yogyakarta: ANDI

Yatini \& Rochadian Maulana. 2013. Analisis Pergerakan Return Saham dan Volume Pergerakan Saham Sebelum dan Sesudah Pengumuman Laporan Keuangan (Penelitian Pada Perusahaan Properti dan Real Estate di Bursa Efek Indonesia Periode Tahun 2010-2011). Jurnal. Institut
Teknologi dan Bisnis Kalbe, XVIII(2): 88-103 